\title{
Molecular, genealogical and morphometric characterisation of the Pallaresa, a Pyrenean relic cattle breed: Insights for conservation
}

\author{
J. Jordana ${ }^{\mathrm{a}, *}$, A. Ferrando ${ }^{\mathrm{a}}$, J. Marmi ${ }^{\mathrm{a}}$, R. Avellanet ${ }^{\mathrm{a}}$, J.A. Aranguren-Méndez ${ }^{\mathrm{a}}$, F. Goyache ${ }^{\mathrm{b}}$ \\ a Departament de Ciència Animal i dels Aliments, Facultat de Veterinària, Universitat Autònoma de Barcelona, E-08193, Bellaterra, Barcelona, Spain \\ b SERIDA, Área de Genética y Reproducción Animal, c/. Camino de los Claveles 604, E-33203 Gijón (Asturias), Spain
}

\section{A R T I C L E I N F O}

\section{Article history:}

Received 19 October 2009

Received in revised form 8 April 2010

Accepted 8 May 2010

\section{Keywords:}

Pallaresa cattle

Genetic variability

Conservation genetics

Morphology

Pedigree analysis

\begin{abstract}
A B S T R A C T
The Pallaresa cattle breed is a native population of beef cattle found in the western regions of the Catalan Pyrenees (Spain). Since the second half of the twentieth century, population size decreased dramatically in favour of the Bruna dels Pirineus breed. At the present time, it is classified as a relic breed on the brink of extinction by the FAO, as only 22 breeding animals remain alive ( 2 bulls and 20 cows). Its importance as genetic and cultural heritage and its contribution in maintaining the landscape and ecosystem, as well as its unquestionable interest as a tourist attraction, make it an irreplaceable element in this area.

In this paper, we present the breed characterisation of the population at the molecular, genealogical and morphological levels, and the comparison and phylogenetic relationships with other local breeds, in order to contribute to the characterisation of this prominent genetic resource.

Genealogical analyses showed that the Pallaresa population is highly inbred. The mean inbreeding for both the whole pedigree and the living population was $18.93 \%$ and $25.71 \%$, respectively. A set of 15 microsatellites were typed on the available Pallaresa individuals to ascertain the genetic variability of the breed at the molecular level and to allow a direct comparison with a set of previously studied 19 local cattle breeds from Spain, Portugal and France. The average number of alleles per locus for the Pallaresa breed (4.3) was the lowest of the analysed breeds and the withinpopulation genetic identity, assessed using molecular coancestry, the highest $(0.437)$. The Pallaresa population showed high levels of differentiation from the other analysed breeds. The lowest kinship distance was assessed for the pairs formed with the Bruna dels Pirineus and Salers breeds $(0.417 \pm 0.010$ and $0.427 \pm 0.011$, respectively). STRUCTURE analysis showed that most Pallares $a$ individuals were assigned to one distinct cluster, showing that the breed gathers a unique genetic background.

Despite its dramatic population scenario, the Pallaresa breed still preserves moderate levels of genetic diversity. The results obtained from the current study can contribute to design appropriate conservation strategies to prevent its extinction in the near future. The implementation of a mating programme involving Pallaresa bulls and Bruna dels Pirineus cows selected according to genetic and morphological closeness to the Pallaresa breed is suggested to prevent the genetic impoverishment of the population.
\end{abstract}

(c) 2010 Elsevier B.V. All rights reserved.
* Corresponding author. Unitat de Ciència Animal, Departament de 17 Ciència Animal i dels Aliments. Facultat de Veterinària, Universitat Autònoma de 18 Barcelona, 08193, Bellaterra, Barcelona, Spain. Tel.: +34 935811217; fax: +34935812106

E-mail address: Jordi.Jordana@uab.cat (J. Jordana).

\section{Introduction}

Local cattle breeds are important genetic resources for agriculture, but many of them are at risk of extinction because of new market and agricultural demands. Unfortunately, some breeds can disappear before being fully documented. This is the case with some autochthonous Iberian breeds, such 
as the Pallaresa, which have suffered a dramatic reduction in their population sizes due to the loss of their economic importance.

The Pallaresa is a white-coated cattle breed that was traditionally distributed through three counties of the western Catalan Pyrenees (Pallars Sobirà, Pallars Jussà and Vall d'Aran), in north-eastern Spain. According to orally transmitted knowledge, it was descended from breeds from northern Europe that arrived in the western Catalan Pyrenees in about 1750. In relation to its morphology and geographical origin, it can be included in the Turdetanus Trunk (Red Convex trunk), together with the Pirenaica breed, which has shared the same habitat for centuries.

The Pallaresa enjoyed its golden age during the first half of the twentieth century, largely due to three main aptitudes: good capacity for field work and the quality of its meat and milk. However, after the beginning of the twentieth century, farmers began to crossbreed Pallaresa cows with dairy cattle breeds imported from Switzerland particularly the BrownAlpine. The result of these crossbreeds, together with selection for meat production, was the Bruna dels Pirineus breed, which is now widely distributed throughout the Catalan Pyrenees. In the middle of the twentieth century, between the 50 and $70 \%$ of cattle in the western Catalan Pyrenees were Pallaresa, but after this the population size decreased dramatically in favour of the Bruna dels Pirineus (Servei de Producció Ramadera, 2003; Parés et al., 2005). The Pallaresa is now classified as a relic breed by the Food and Agriculture Organization of the United Nations (FAO, http://www.fao. org/dad-is/). At the moment, only twenty-two breeding animals remain alive (two bulls and twenty cows), grouped in a single herd in the village of Besan (Vall Ferrera, Pallars Sobirà).

The historical, cultural and genetic heritage of the Pallaresa cattle breed is unquestionable. Moreover, productively, the Pallaresa is quite similar to the Bruna dels Pirineus and it is well adapted to extreme mountainous environments. The withers height for adult cows is around $136 \mathrm{~cm}$; the weight of living individuals ranges from 575 to 625 for cows, and from 625 to $650 \mathrm{~kg}$ for bulls. Calves are fattened up and slaughtered at one year-old. The carcass yield is 60\% (carcass weight around 350-375 kg) (Parés et al., 2005).

The loss of this autochthonous breed would represent the extinction of selected genotypes for adaptation to mountainous regions, contributing to the genetic impoverishment of the species. Despite its long history, the Pallaresa is not yet included in the Spanish Official Breed Catalogue. In addition, neither genetic nor morphological studies have been previously performed to characterise this breed. Due to the extreme risk of extinction, it is necessary to obtain data from this breed urgently, at least in order to document its main morphological and genetic characteristics and also to explore whether its recovery is possible. For this reason, in 2001, the Department of Agriculture, Food and Rural Action (DAR) of the Catalan Government, in collaboration with the Universitat Autònoma de Barcelona (UAB), began the Pallaresa Cattle Breed Conservation Programme (Avellanet et al., 2002). The objectives of this Conservation Programme were the genetic and morphological characterisation of the Pallaresa population to describe the breed standard, the levels of genetic variability and its phylogenetic relationships. Here we report the results obtained since the beginning of the Conservation Programme and discuss the possibilities for recovering the Pallaresa cattle breed.

\section{Material and methods}

Genetic characterisation was carried out using pedigree analysis together with microsatellite markers. We analysed the information contained in the Pallaresa cattle Herd Book, in which 66 animals were registered between 1962 and 2009. This information belonged to one only herd located at Besan (Vall Ferrera, Pallars Sobirà). The level of pedigree completeness was characterised by computing the maximum number of generations and full generations traced, as well as equivalent generations. In order to characterise the genetic variability of the herd, we computed the effective number of founders $\left(f_{\mathrm{e}}\right)$, the effective number of ancestors $\left(f_{\mathrm{a}}\right)$, the individual inbreeding coefficient $(F)$ and the individual average relatedness coefficient (AR). The living population (31 individuals) was used as reference population for the computation of the parameters $f_{\mathrm{e}}$ and $f_{\mathrm{a}}$. These parameters are detailed in Gutiérrez et al. (2005a) and were computed using ENDOG (current version 4.5) software (Gutiérrez and Goyache, 2005).

We obtained blood samples from twenty individuals (18 cows and 2 bulls) for molecular genetic analyses. DNA was extracted according to a standard phenol-chloroform protocol (Ausubel et al., 1987). Fifteen microsatellite loci were amplified: CSSM66, ETH10, ETH152, ETH225, ETH3, HEL1, HEL5, HEL9, ILSTS5, INRA23, INRA35, INRA37, INRA5, INRA63 and TGLA44 according previous analyses (Cañón et al., 2001; Beja-Pereira et al., 2003; Jordana et al., 2003). PCR products were run in an Applied Biosystems 3100 or 3730 DNA Sequencer and analysed with GENESCAN or GENEMAPPER Analysis software (Applied Biosystems), using internal-size standards. Alleles were coded according to reference samples.

Statistical analyses consisted of estimates of genetic diversity, population structure, assignment tests and phylogenetic inference. We computed unbiased expected $\left(H_{\mathrm{E}}\right)$ and observed $\left(H_{\mathrm{O}}\right)$ heterozygosity and allelic frequencies with GENETIX v.4.05 (Belkhir et al., 2001). We tested each locus for heterozygote deficiency estimating the F-statistic value analogue to Wright's $F_{\text {IS }}$ with FSTAT for Windows v.2.9.3 (Goudet, 1995). The polymorphism information content (PIC) for each microsatellite locus, and the raw and the rarefacted (adjusted for sampling size; Hurlbert, 1971) number of alleles per locus were computed using MOLKIN v.3.0 (Gutiérrez et al., $2005 \mathrm{~b})$. The kinship distance $\left(D_{\mathrm{k}}\right)$ and coancestry coefficients ( $f_{i j}$, Caballero and Toro, 2002) between breeds and within the Pallaresa breed were also obtained with this software. When needed, confidence on the parameter estimates were obtained by means of 1000 bootstrapping replicates. To determine the usefulness of the markers used in this study for parentage analyses, the non-exclusion probability of the first parent (NEP1) for each locus and overall the panel were calculated with CERVUS v3.0.3 (Kalinowski et al., 2007). The MICRO-CHECKER software (Van Oosterhout et al., 2004) was used to test for the presence of null alleles (non amplifying alleles) in the Pallaresa breed. The BOTTLENECK software (Piry et al., 1999) was used to test the reduction of the effective Pallaresa population size. Tests were performed assuming the Stepwise Mutation Model (SMM; Ohta and Kimura, 1973) and the Two- 
Phases Model (TPM; Di Rienzo et al., 1994). In the last case, we used the values of $95 \%$ of proportion of SMM in TPM and 12 for TPM variance, according to Piry et al. (1999).

Phylogenetic relationships between the Pallaresa and other cattle breeds were inferred by neighbour-joining method (Saitou and Nei, 1987) using Reynolds genetic distance, $D_{\mathrm{R}}$, (Reynolds et al., 1983) with POPULATIONS v.1.2.28 (Langella, 2002). The $D_{\mathrm{R}}$ distance is preferably used when genetic drift is assumed to be the main genetic differentiation factor and the divergence time between populations is short (e.g. Laval et al., 2002). The robustness of the phylogeny was obtained by means of 1000 bootstrap permutations. To perform the phylogenetic analysis we included allelic frequencies from the following breeds previously studied by Cañón et al. (2001), Aranguren-Méndez et al. (2002) and Jordana et al. (2003), and distributed throughout Spain (Alistana, Asturiana de las Montañas, Asturiana de los Valles, Avileña, Bruna dels Pirineus, Mallorquina, Morucha, Pirenaica, Retinta, Sayaguesa and Tudanca), Portugal (Alentejana, Barrosã, Maronesa, Mertolenga, and Mirandesa) and France (Aubrac, Gasconne and Salers). The allele size standardization was achieved by typing reference samples. Pair-wise $F_{\mathrm{ST}}$ and the estimate of gene flow (as the effective number of migrants exchanged per generation, $\mathrm{Nm}$ ) among Pallaresa and the other cattle breeds were computed with ARLEQUIN v.3.1 (Excoffier et al., 2005). STRUCTURE v2.3.1 software (Pritchard et al., 2000; Falush et al., 2003) was used to explore the population structure among Bruna dels Pirineus (Bruna from now on), Pallaresa and Pirenaica breeds, whose populations are geographically very close. We assumed that there were three real populations $(K=3)$, one per breed, but no prior population information was provided for any individual. The assignment of each individual to an inferred cluster was tested under the admixture model, allowing individuals to have mixed ancestry. The length of burn-in period was set to 20,000 and was followed by 100,000 MCMC (Markov chains Monte Carlo) steps. All other parameters were set to default. Values of $Q$ which define the proportion of each individual's genome that originates from each cluster, were averaged over 20 iterations. Individuals with a threshold $Q>0.80$ were assigned to one cluster, or to more clusters if the proportion of membership was $Q<0.80$.

Morphological characterisation was performed by means of morphometric measurements of twelve adult cows aged over three years. We analysed a total of 26 biometric variables measured by the same researcher using a zoometric stick, a compass and a tape measure, following the order indicated in Table 4. Statistic analysis was performed by descriptive statistics using SAS package (SAS, 2004).

\section{Results}

\subsection{Pedigree analysis}

In 2009, a total of 66 individuals belonging to the same herd was registered in the Pallaresa breed Herd Book. The sex ratio between males and females was close to 1:2 (21 males and 45 females). The living population consisted of 31 individuals (22 females). The base population consisted of nine founders eight females and a single male - from which all other ancestors of living individuals were descended. As a consequence, all non- founder individuals turned out to be related. The maximum number of generations and the maximum number of full generations traced were 6 and 4, respectively. The mean generation equivalent was 2.78 for the whole data set.

Each founder produced one or two registered descendants. All the variability retained in the living population came from eight ancestors (including six founders): a non-founder male and seven females. However, the effective number of ancestors was three. Only one male (named "Pallarés") and one half-sibling female were strictly first-generation descendants. All other generations overlapped. The male Pallarés explained $58.9 \%$ of the genetic variability of the breed and $59.9 \%$ of the living population. As the pedigree tree became deeper, the percentage of inbred animals increased very quickly. The mean inbreeding $(F)$ was $18.93 \%$ and the average relatedness (AR) was $43.94 \%$. These values increased to $25.71 \%$ and $51.67 \%$ in the living population, respectively (see Table 1 for a summary). All individuals with two complete generations traced (all grandparents known) were inbred. In individuals with four complete generations recorded, the mean inbreeding coefficient and the average relatedness reached $34.23 \%$ and $56.55 \%$, respectively.

\subsection{Microsatellite analysis}

All of the 15 microsatellites amplified were polymorphic in the population. The number of alleles ranged from two (ILSTS5) to seven (CSSM66) (Table 2). Despite its extremely low population size, the Pallaresa breed still preserves some alleles that exist at low frequencies in some of the other cattle breeds analysed. This was the case with allele 209 of locus ETH10 which was shared with the Mirandesa breed (allele frequency $=0.010$ ) and allele 140 of locus INRA37 which was shared with the Alentejana (allele frequency $=0.02$ ) and Gasconne (allele frequency $=0.03$ ) breeds. The average number of alleles per locus found in the Pallaresa was equal to 4.3 . The average expected genetic diversity $\left(H_{\mathrm{E}}\right)$ for all loci was 0.579, and it ranged from 0.142 (ILSTS5) to 0.786 (CSSM66). Three loci, ETH10, HEL1 and INRA35 significantly deviated from the Hardy-Weinberg equilibrium (HWE) (Table 2). After applying Bonferroni correction for 15 tests, only INRA35 showed a significant departure from the HWE with a high deficit of heterozigots $\left(F_{\mathrm{IS}}=0.740, P<0.01\right)$. Overall loci, the breed was in equilibrium $\left(F_{\mathrm{IS}}=0.006\right.$, n.s. $)$,

Table 1

Main genealogical parameters computed for the whole population included in the Pallaresa cattle breed Herd Book.

\begin{tabular}{lc}
\hline Parameters calculated & Value \\
\hline Number of individuals registered on the herd book & 66 \\
Number of founders & 9 \\
Base population & 9 \\
Effective size of the base population & 4.74 \\
Effective number of founders $\left(f_{\mathrm{e}}\right)$ & 4 \\
Effective number of ancestors $\left(f_{\mathrm{a}}\right)$ & 3 \\
Mean inbreeding $(F)$ & $18.93 \%$ \\
Mean inbreeding of living population $\left(F_{\text {living }}\right)$ & $25.71 \%$ \\
Mean average relatedness $(A R)$ & $43.94 \%$ \\
Mean average relatedness of living population $\left(\mathrm{AR}_{\text {living }}\right)$ & $51.67 \%$ \\
Mean generation equivalent & 2.78 \\
Mean inbreeding increase per generation equivalent & $7.91 \%$ \\
\hline
\end{tabular}


Table 2

Genetic diversity values for the Pallaresa cattle breed. Abbreviations: No A, total number of observed alleles; $H_{\mathrm{E}}$, expected heterozygosity (unbiased estimate); $H_{\mathrm{O}}$, observed heterozygosity; PIC, polymorphism information content; NE-P1, non-exclusion probability of the first parent; $F_{\mathrm{IS}} \approx F$ within-population inbreeding estimate (n.s., non significant; ${ }^{*} P<0.05 ;{ }^{* * *} P<0.001$ ).

\begin{tabular}{|c|c|c|c|c|c|c|c|}
\hline Locus & No $A$ & Size Range (pb) & $H_{\mathrm{E}}$ & $H_{\mathrm{O}}$ & PIC & NE-1P & $F_{\mathrm{IS}} \approx F$ \\
\hline CSSM66 & 7 & 181-199 & 0.786 & 0.800 & 0.730 & 0.627 & -0.018 \\
\hline ETH10 & 5 & $209-223$ & 0.540 & 0.700 & 0.482 & 0.852 & $-0.307^{*}(\text { n.s. })^{a}$ \\
\hline ETH152 & 5 & $193-205$ & 0.689 & 0.600 & 0.616 & 0.746 & 0.131 \\
\hline ETH225 & 5 & $143-151$ & 0.694 & 0.650 & 0.636 & 0.731 & 0.064 \\
\hline ETH3 & 4 & $117-127$ & 0.599 & 0.600 & 0.499 & 0.825 & -0.002 \\
\hline HEL1 & 3 & $105-111$ & 0.614 & 0.350 & 0.514 & 0.821 & $0.436^{*}(\text { n.s. })^{a}$ \\
\hline HEL5 & 6 & $151-167$ & 0.669 & 0.800 & 0.611 & 0.752 & -0.202 \\
\hline HEL9 & 3 & $153-163$ & 0.630 & 0.650 & 0.539 & 0.812 & -0.033 \\
\hline ILSTS5 & 2 & $184-186$ & 0.142 & 0.150 & 0.129 & 0.990 & -0.056 \\
\hline INRA5 & 3 & $139-143$ & 0.579 & 0.526 & 0.493 & 0.841 & 0.093 \\
\hline INRA23 & 4 & $205-213$ & 0.703 & 0.850 & 0.632 & 0.738 & -0.217 \\
\hline INRA35 & 3 & $102-110$ & 0.397 & 0.105 & 0.350 & 0.925 & $0.740^{* * *}\left({ }^{* *}\right)^{\mathrm{a}}$ \\
\hline INRA37 & 4 & $126-140$ & 0.191 & 0.200 & 0.180 & 0.982 & -0.048 \\
\hline INRA63 & 4 & $175-183$ & 0.763 & 0.900 & 0.696 & 0.679 & -0.185 \\
\hline TGLA44 & 6 & $146-172$ & 0.685 & 0.750 & 0.609 & 0.745 & -0.098 \\
\hline MEAN ( \pm s.d. $)$ & 4.3 & & $0.579 \pm 0.192$ & $0.575 \pm 0.259$ & 0.514 & 0.034 & 0.006 n.s. \\
\hline
\end{tabular}

s.d., standard deviation.

a After applying Bonferroni correction.

even after excluding INRA35 ( $F_{\mathrm{IS}}=-0.030$, n.s.). The polymorphism information content (PIC) and the probability of non-exclusion of the first parent are given for each locus in Table 2. The combined probability of non-exclusion of the first parent for a panel of 15 markers was 0.034 (and 0.037 after excluding INRA35).

Two loci, INRA35 and HEL1, showed signs of the presence of null alleles at the $95 \%$ of confidence limit, but only INRA35 was significant at the $99 \%$ confidence level. Simulations have shown that null alleles can slightly overestimate $F_{\mathrm{ST}}$ values and have a moderate effect on the accuracy of assignment tests. However, the number of loci and level of genetic differentiation have more significant effect on the accuracy of assignment testing than the presence of null alleles. Thus, loci affected by null alleles can be included in population genetic studies, although they should be used with caution (Carlsson, 2008). Since INRA35 showed strong evidence of the presence of null alleles, all records were excluded for this locus, but HEL1 was maintained. Subsequent analyses were performed with 14 loci.

No evidence for a recent bottleneck was detected in the Pallaresa. Analysis performed under the Sign Test and the Wilcoxon Sign-Rank Test with the TPM and SMM models were not significant.

Bruna and Salers showed the lower kinship distance values with Pallaresa $\left(D_{\mathrm{k}}=0.417 \pm 0.010\right.$ and $D_{\mathrm{k}}=0.427 \pm 0.011$, respectively), while the most distant breeds were Tudanca $\left(D_{\mathrm{k}}=0.493 \pm 0.011\right)$ and Sayaguesa $\left(D_{\mathrm{k}}=0.483 \pm 0.011\right)$. Within-breed kinship distance was lower for Pallaresa $\left(D_{\mathrm{k}}=\right.$ $0.259 \pm 0.013$ ) than other breeds (Mirandesa: $D_{\mathrm{k}}=0.302 \pm$

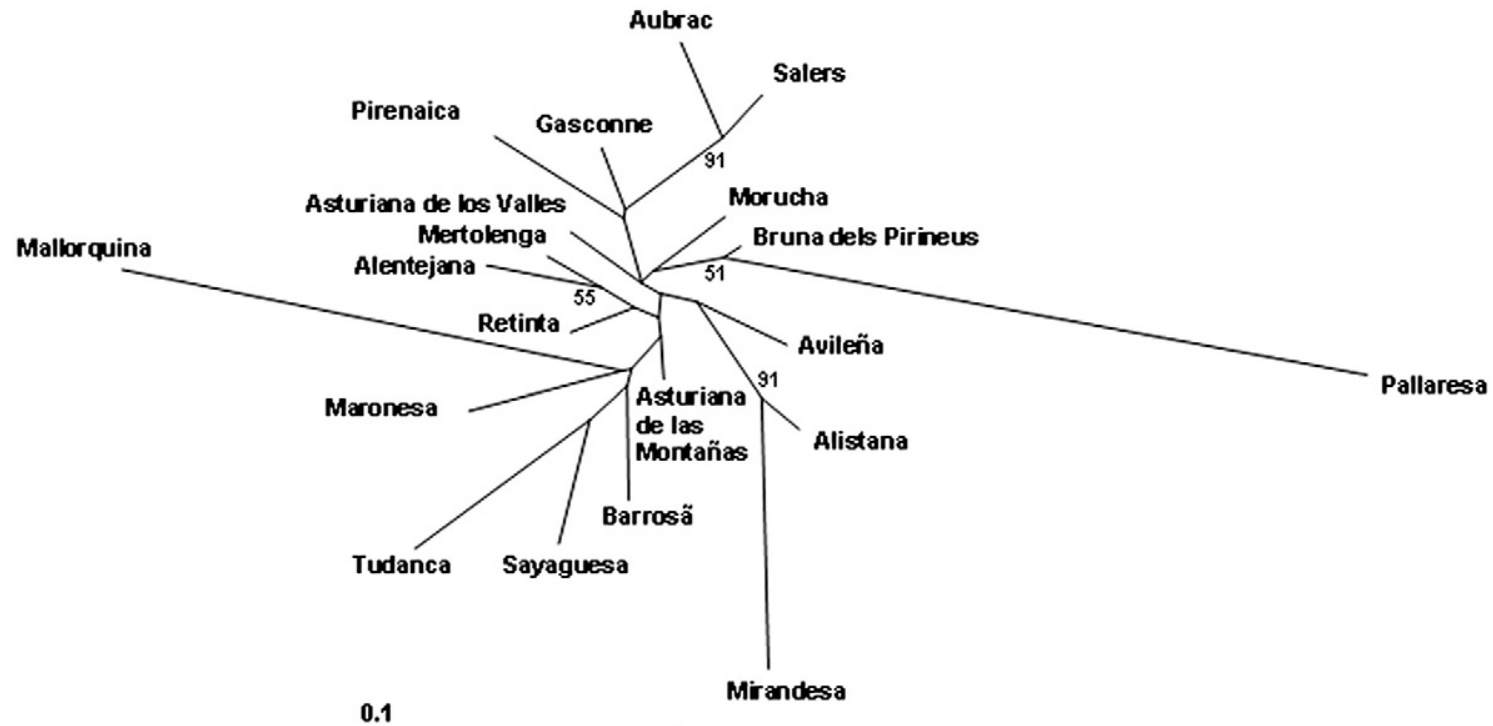

Fig. 1. Neighbour-joining tree based on Reynolds genetic distances showing the phylogenetic relationships of the Pallaresa cattle breed. Bootstrap values above $50 \%$ are indicated. 
0.010; Morucha $D_{\mathrm{k}}=0.387 \pm 0.010$ ). The two breeds that showed higher coancestry coefficients with Pallaresa were also Bruna and Salers $\left(f_{i j}=0.270 \pm 0.007\right.$ and $f_{i j}=0.272 \pm$ 0.009 , respectively), whereas those with the lower were Tudanca $\left(f_{i j}=0.198 \pm 0.008\right)$ and Sayaguesa $\left(f_{i j}=0.197 \pm\right.$ 0.007). Within-breed coancestry was much higher for Pallaresa than other breeds. Within-breed coancestries tend to increase in population with the lowest size due to the highest contribution of self-coancestries $\left(s_{i i}\right)$ to within-population coancestry $\left(f_{i i}\right)$. Thus, sample size was equalised to 19 individuals for all breeds. However, Pallaresa $\left(f_{i i}=0.437 \pm 0.012\right)$ still clearly fell out of the range of other breeds (Barrosã, $f_{i i}=0.290 \pm 0.010$; Aubrac, $f_{i i}=0.406 \pm 0.018$ ).

Fig. 1 shows the phylogenetic relationships of the Pallaresa with other cattle breeds from France, Portugal and Spain (see Material and methods). The Pallaresa showed a great genetic differentiation clustered together the Bruna with a bootstrap value of $51 \%$. This is consistent with the minimum $F_{\mathrm{ST}}$ genetic distance obtained $\left(F_{\mathrm{ST}}=0.112\right)$ and the maximum gene flow found ( 2 migrants per generation) between these two breeds (Table 3). All $F_{\mathrm{ST}}$ values of the matrix were statistically significant $(P<0.001)$.

The assignment tests of individuals to different clusters were performed with STRUCTURE, and assuming that there were three real distinct populations, one per breed. Mean proportion of membership of each breed fell in one distinct cluster (cluster 1: Bruna, $Q=0.84$; cluster 2: Pallaresa, $Q=0.96$; cluster 3: Pirenaica, $Q=0.85$ ) (see Fig. 2). One Pallaresa individual had partial ancestry in cluster $2(0.665)$ and cluster 3 (0.216). Ten Pirenaica and 12 Bruna individuals presented a proportion of membership to their clusters below 0.80 . These Pirenaica individuals were fully or partially assigned to cluster 1 ( $Q$ : $0.30-0.91)$ but not to cluster $2(Q<0.110)$. Eight Bruna individuals were fully or partially assigned to cluster 3 ( $Q: 0.19-0.98)$, and four individuals were partially assigned to cluster $2(Q: 0.24-0.50)$.

\subsection{Morphological analysis}

Table 4 shows average values of 26 morphologic measures and their standard errors, coefficients of variation and minimum and maximum values.

\section{Discussion}

Despite its extremely low population size, the sole extant population of the Pallaresa cattle breed still preserves moderate levels of genetic diversity. The average number of alleles per locus found in the Pallaresa was lower than the range of values obtained in other western European cattle breeds using the same microsatellite markers (5.5 for Mirandesa; 7.2 for Gasconne) (Cañón et al., 2001). This parameter is one of the most important in conservation genetics because it provides information on the long-term evolutionary potential of a population (Petit et al., 1998). However, this is greatly affected by sampling size, particularly in cases such as that presented here in which the Pallaresa individuals genotyped are $40 \%$ of the other cattle breeds used as reference. After rarefaction, the average number of allele per locus $\left(A_{(38)}\right.$; see Table 3$)$ fell outside the range of the other cattle breeds analysed with the same 14 markers (4.7, for Mallorquina; 6.4, for Morucha),

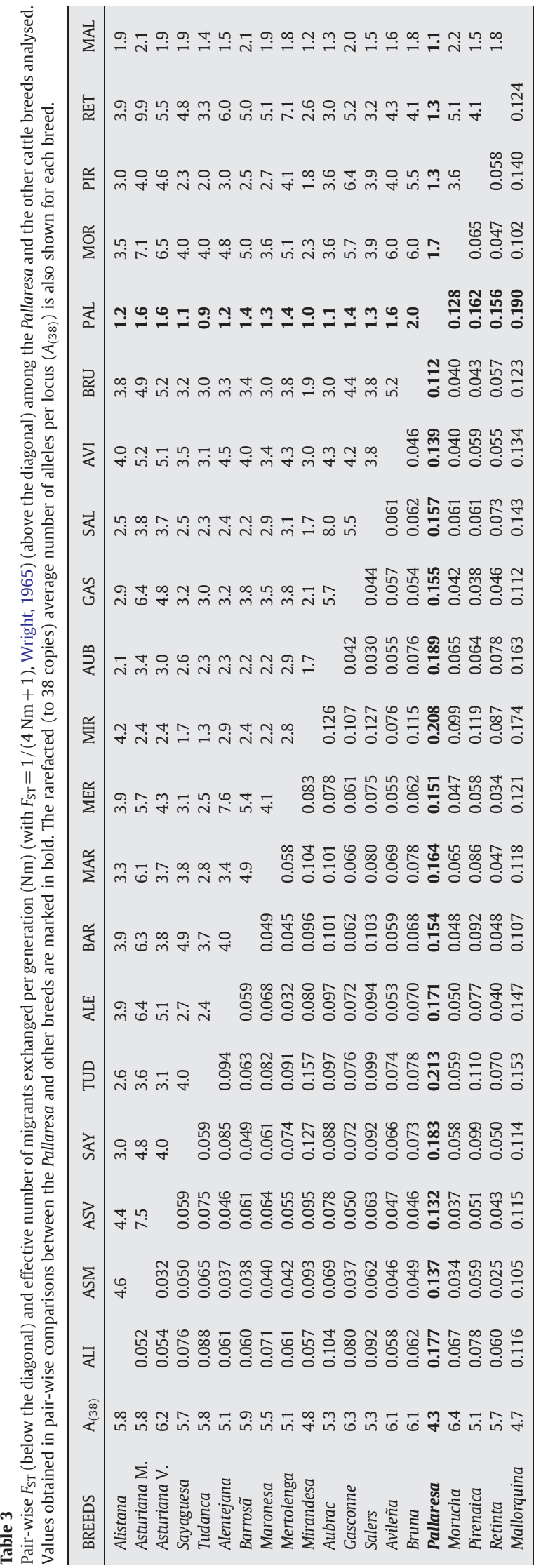




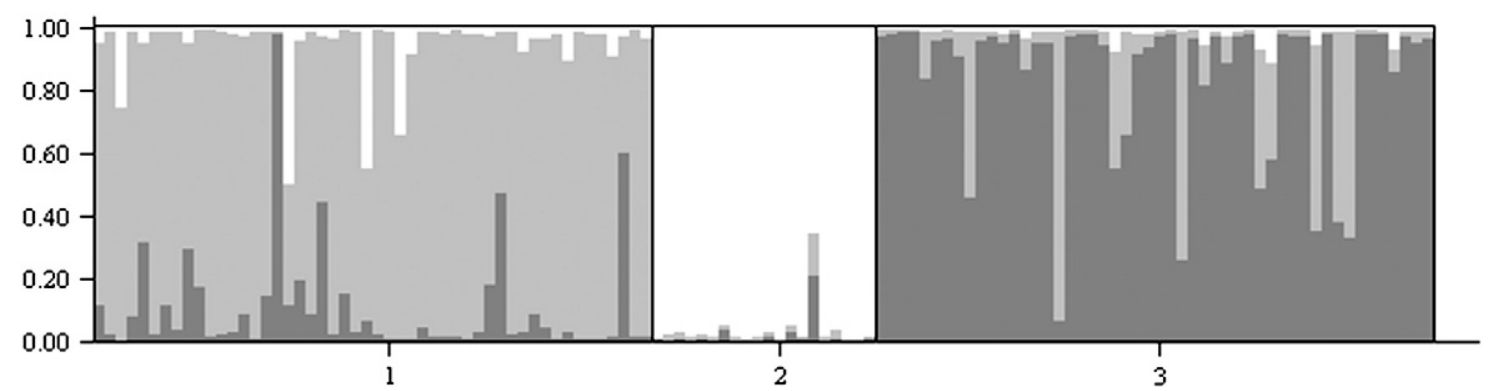

Fig. 2. Bar plots obtained from STRUCTURE, analysing the population structure of Bruna dels Pirineus (1), Pallaresa (2) and Pirenaica (3) breeds, with $K=3$ clusters. Each individual is represented by a vertical line partitioned into $K$ coloured segments.

indicating the delicate situation for the viability of the Pallaresa population. However, the mean observed heterozygosity we found $\left(H_{\mathrm{O}}=0.58\right.$. ) fell in the range obtained by the European Cattle Genetic Diversity Consortium (2006) for other Spanish Breeds (Mallorquina, $H_{\mathrm{O}}=0.52$; Asturiana de los Valles, $H_{\mathrm{O}}=0.70$ ). The global estimate of $F_{\mathrm{IS}}$ did not deviate significantly from the Hardy-Weinberg equilibrium, and three loci (HEL1, INRA35 and ETH10) presented significant departures from HWE, even if only INRA35 was significant after applying Bonferroni correction for multiple tests. The results obtained at locus INRA35 and HEL1 pointed out to the presence of null alleles, especially at locus INRA35, leading to false observations of homozygotes, as suggested for INRA35 by Kantanen et al. (2000) and Jordana et al. (2003). The locus INRA35 should therefore be removed from parentage analysis and HEL1 must be treated with caution as well, until confirming if it is really affected by the presence of null alleles.

Table 4

Values of morphometric measures (in centimetres) in the Pallaresa cattle breed. SE, standard error; CV, coefficient of variation; Min, minimum value; Max, maximum value.

\begin{tabular}{|c|c|c|c|c|c|}
\hline Morphometric variables & Mean & SE & $\mathrm{CV}$ & Min & Max \\
\hline Withers height & 131.42 & 2.93 & 7.73 & 117.5 & 157.0 \\
\hline Back height & 132.42 & 2.58 & 6.76 & 120.0 & 156.0 \\
\hline Rump height & 134.79 & 2.85 & 7.32 & 119.0 & 162.0 \\
\hline Pelvis height & 136.50 & 2.69 & 6.83 & 122.0 & 162.0 \\
\hline Root of tail height & 136.21 & 2.66 & 6.77 & 121.0 & 161.0 \\
\hline Length diameter & 144.96 & 3.02 & 7.21 & 122.0 & 157.0 \\
\hline Back-sternal diameter & 72.33 & 2.84 & 13.63 & 60.0 & 97.0 \\
\hline Diameter between ribs & 44.42 & 1.12 & 8.73 & 39.5 & 50.0 \\
\hline Thoracic diameter & 49.29 & 1.90 & 13.34 & 39.0 & 60.0 \\
\hline Rump width & 47.67 & 1.16 & 8.41 & 40.0 & 54.0 \\
\hline Rump length & 47.00 & 1.16 & 8.53 & 40.0 & 53.0 \\
\hline Head length & 50.46 & 1.06 & 7.29 & 43.0 & 54.5 \\
\hline Head depth & 35.17 & 0.79 & 7.75 & 30.0 & 40.0 \\
\hline Skull length & 13.92 & 0.39 & 9.79 & 12.0 & 16.0 \\
\hline Face length & 33.54 & 0.72 & 7.42 & 29.0 & 37.0 \\
\hline Skull width & 20.29 & 0.58 & 9.88 & 16.0 & 23.0 \\
\hline Face width & 11.67 & 0.22 & 6.42 & 10.0 & 13.0 \\
\hline Thoracic perimeter & 180.08 & 4.16 & 8.01 & 160.0 & 198.0 \\
\hline Knee perimeter & 36.12 & 0.74 & 7.11 & 32.0 & 40.0 \\
\hline Cannon perimeter & 20.71 & 0.62 & 10.37 & 18.0 & 25.0 \\
\hline Fetlock-joint perimeter & 27.79 & 0.67 & 8.38 & 25.0 & 33.0 \\
\hline Pastern perimeter & 30.29 & 0.84 & 9.66 & 27.0 & 37.0 \\
\hline Coronet perimeter & 29.92 & 1.13 & 13.10 & 25.0 & 37.0 \\
\hline Elbow-roll distance & 21.58 & 0.73 & 11.76 & 18.0 & 26.0 \\
\hline Hock perimeter & 47.62 & 0.89 & 6.47 & 41.0 & 51.5 \\
\hline Ear length & 22.50 & 0.51 & 7.93 & 19.0 & 26.0 \\
\hline
\end{tabular}

The non-significance of $F_{\mathrm{IS}}$ is not an unexpected result because the breed is composed by a single family unit. Thus, even if individuals are inbred, they still can be in HWE within the family. However, within-breed kinship distance and molecular coancestry coefficient show that Pallaresa individuals are much more genetically closer from each other than individuals from any other breed analysed. A consistent estimate of consanguinity, which is frequently more reliable than molecular data, may be obtained from pedigree information. In this case, we obtained a value of $F$ for the living population equal to $25.71 \%$ which was approximately between one- and two-fold greater than those reported by the Final Report FAIR1 CT95 702, cited by Jordana et al. (2003). In these cases, the lowest value was found in the Aubrac $(F=0.9 \%)$ and the highest in the Alentejana and Sayaguesa breeds $(F=7.0 \%)$. It must be taken into account that our result may be underestimated because of the incompleteness of the genealogical information available.

The inbreeding coefficient of founders and both individuals strictly from the first generation was set to $F=0$, due to the lack of genealogical data from the base population. However, founders could have been relatives and possibly inbred, so the values of $F$ and AR were possibly underestimated, particularly in the first generations. All living individuals were inbred and closely related. This is a consequence of the small size of the population, but also due to the unbalancing contribution of ancestors to subsequent generations and the strong disequilibrium between males and females at the deepest levels of genealogical tree. Most generations overlapped due to the scarce number of reproductive males, and this led to crossing between close relatives. As a consequence, almost $60 \%$ of the genetic variability of the living population originated from one male. High levels of average relatedness between individuals make it unlikely that inbreeding levels can be reduced. In addition, we predict an important loss of molecular genetic diversity in a small number of generations. For instance, almost $33 \%$ of alleles remained at very low frequencies $(<0.1)$ and they may easily become extinct in a short time due to the stochastic effects of genetic drift.

However, it seems a paradox that we did not detect evidence of a bottleneck signature in the Pallaresa population. Despite the extreme reduction in its population size, the genetic diversity would have not been significantly reduced over recent decades. Luikart and Cornuet (1998) precise that bottleneck may not be detected if there are not enough individuals sampled to reach statistical power, they are not representative 
of the bottlenecked population, or the population is not completely isolated. The number of individuals and markers used in this study were in the range recommended by Piry et al. (1999) to reach high power with the Wilcoxon test (15-40 individuals and $10-15$ polymorphic loci), and it can be assumed that sampled individuals are representative of the breed. Therefore, the signal of a bottleneck may have been obscured by the existence of gene flow. However, according to the Herd Book, there are not crossbred individuals within the Pallaresa breed since the establishment of the herd. Hence, the levels of genetic diversity detected can result from the fact that the herd was created by gathering unrelated animals (according to breed type; principally uniform white coat) from different localities. Another explanation may be the introgression of genes from the Bruna breed into ancestors of the founder group. Similar results and conclusions have been reported in another endangered Catalan cattle breed, the Alberes (Casellas et al., 2004). Assignment tests performed with STRUCTURE also show that Pallaresa individuals clustered in a single and distinct group with high $Q$ values. One individual was partially assigned to the Pirenaica cluster, which can be a residual sign of a mixed ancestry of one or more founders. Bruna and Pirenaica mainly clustered separately from each other, though some individuals could not have been clearly assigned to one unique cluster. The few individuals that were partially assigned to the Pallaresa cluster belonged to the Bruna breed.

According to kinship distances and coancestry coefficients, the genetically closest breeds to Pallaresa were Bruna and Salers. The neighbour-joining tree (Fig. 1) and $F_{\mathrm{ST}}$ values (Table 3) were consistent with a close genetic relationship between Pallaresa and Bruna. The Bruna is partially descended from the Pallaresa breed. However, even if Pallaresa and Bruna clustered together (Fig. 1), the genetic differentiation between them was considerable. According to Cañón et al. (2001) and Jordana et al. (2003), genetic drift can explain the genetic diversity of western European cattle breeds, contributing to their differentiation. This is supported by the statistically significant $F_{\mathrm{ST}}$ values obtained (Table 3 ). The stronger genetic differentiation of the Pallaresa breed would be a result of the change of allelic frequencies or the extinction of some alleles due to its reduced population size. Migration is another evolutionary force that homogenises breeds. Due to its geographical proximity, the Bruna is the most likely breed to interbreed with the Pallaresa. According to our estimates, the upper limit of the number of migrants per generation allowed to maintain the genetic differentiation between Pallaresa and Bruna is around two (Table 3). However, this result should be taken with caution because indirect gene flow methods estimated using molecular markers are often ambiguous and prone to multiple interpretations (Bossart and Prowell, 1998).

Beja-Pereira et al. (2003) found a more remarkable genetic differentiation among breeds from northern Iberia than among those from other regions on the Iberian Peninsula. This occurs because in northern Iberia the agricultural system consists of small herds located in isolated regions due to geographical and environmental barriers. This fact makes northern regions of the Iberian Peninsula, such as the Pyrenees, an important reservoir of diversity, and breeds and populations living in these environments should be our priority for conservation purposes. For these reasons, the recovery of the Pallaresa cattle breed is necessary. Thus, the management of the breed must include a careful planning of crossings between individuals. As preliminary actions, we suggest to increase the number of bulls to avoid regular bottlenecks in the male line, and mating the most unrelated animals in the population according to their molecular and genealogical coancestry coefficients to prevent an increase in inbreeding and average relatedness, and to maximize the gene diversity of the breed. However, the impact of these actions are limited due to the fact that whole breed is composed by close relatives. Therefore, crossbred individuals could be allowed to preserve the genetic pool of Pallaresa, and to prevent the genetic impoverishment of the breed by controlled mating among mixed and pure individuals. Bruna cows would be the appropriate choice to interbreed with Pallaresa bulls because they are genetically closer and some individuals may have recent mixed ancestry with Pallaresa. Following a similar approach to that recently proposed by Sobral et al. (2009) for the recovery of an extinct bovine population from the Algarve region of Portugal, white-coated individuals belonging to the Bruna dels Pirineus population would be suitable to interbreed with Pallaresa if they were selected according to likeness in the morphometric variables showed in Table 4. Bayesian clustering (STRUCTURE) could be applied to select individuals with higher levels of mixed ancestry with Pallaresa.

\section{Conclusion}

Despite its extremely low population size and high consanguinity, the sole extant population of the Pallaresa cattle breed still preserves relatively good levels of genetic diversity. The proven fact that the northern regions of the Iberian Peninsula, such as the Pyrenees, are an important reservoir of diversity, endorses the priority of the recovery of the Pallaresa breed for conservation purposes. Thus, the management of the breed must include a careful planning of crossings between individuals, taking into account the average relatedness between candidate pairs of reproductive individuals. In addition, a minimal number of matings ( $<2$ per generation) between Pallaresa bulls and Bruna dels Pirineus cows selected according to genetic and morphological closeness could be allowed to prevent the genetic impoverishment of the Pallaresa population, and to increase their effective population size.

\section{Acknowledgements}

We wish to thank the breeder Ignasi Sinfreu Canturri for providing samples of the animals and their genealogical data. This work has been supported by the Department of Agriculture, Food and Rural Action (DAR) of the Government of Catalonia.

\section{References}

Aranguren-Méndez, J.A., Jordana, J., Avellanet, R., Torrens, M., 2002. Genetic diversity measures of local cattle Majorcan breed for conservation purposes. Rev. Cient-Fac. Cien. V. 12, 358-366.

Ausubel, F.M., Brent, R., Kingston, R.E., Moore, D.D., Seidman, G.G., Smith, J.A., Struhl, K., 1987. Current Protocols in Molecular Biology. Green Publishing Associates and Wiley-Interscience, New York, USA.

Avellanet, R., Aranguren-Méndez, J.A., Jordana, J., 2002. Programa de recuperación de la raza bovina Pallaresa. III Congreso Ibérico sobre los Recursos Genéticos Animales, Madrid: El Arca, 5, p. 22. 
Beja-Pereira, A., Alexandrino, P., Bessa, I., Carretero, Y., Dunner, S., Ferrand, N. Jordana, J., Laloë, D., Moazami-Goudarzi, K., Sánchez, A., Cañón, J., 2003. Genetic characterization of Southwestern European bovine breeds: historical and biogeographical reassessment with a set of 16 microsatellites. J. Hered. 94, 243-250.

Belkhir, K., Borsa, P., Chikhi, L., Raufaste, N., Bonhomme, F., 2001. GENETIX 4.02, Logiciel sous Windows TM pour la Génétique des Populations. Laboratoire Génome, Populations, Interactions: CNRS UMR 5000, Université de Montpellier II, Montpellier, France.

Bossart, J.L., Prowell, D.P., 1998. Genetic estimates of population structure and gene flow: limitations, lessons and new directions. Trend Ecol. Evol. 13, 202-206.

Caballero, A., Toro, M.A., 2002. Analysis of genetic diversity for the management of conserved subdivided populations. Conserv. Genet. 3 , 289-299.

Cañón, J., Alexandrino, P., Bessa, I., Carleos, C., Carretero, Y., Dunner, S., Ferrand, N., García, D., Jordana, J., Laloë, D., Pereira, A., Sánchez, A., Moazami-Goudarzi, K., 2001. Genetic diversity measures of local European beef cattle breeds for conservation purposes. Genet. Sel. Evol. $33,311-332$.

Carlsson, J., 2008. Effects of microsatellite null alleles on assignment testing. J. Hered. 99, 616-623.

Casellas, J., Jiménez, N., Fina, M., Tarrés, J., Sánchez, A., Piedrafita, J., 2004 Genetic diversity measures of the bovine Alberes breed using microsatellites: variability among herds and types of coat colour. J. Anim. Breed. Genet. 121, 101-110.

Di Rienzo, A., Peterson, A.C., Garza, J.C., Valdes, A.M., Slatkin, M., Freimer, N.M. 1994. Mutational processes of simple-sequence repeat loci in human populations. Proc. Natl Acad. Sci. USA 91, 3166-3170.

European Cattle Genetic Diversity Consortium, 2006. Marker-assisted conservation of European cattle breeds: an evaluation. Anim. Genet. 37, 475-481.

Excoffier, L., Laval, G., Schneider, S., 2005. Arlequin ver. 3.0: an integrated software package for population genetics data analysis. Evolutionary Bioinformatics Online 1, 47-50.

Falush, D., Stephens, M., Pritchard, J.K., 2003. Inference of population structure using multilocus genotype data: linked loci and correlated allele frequencies. Genetics 164, 1567-1587.

Goudet, J., 1995. FSTAT (version 1.2): a computer program to calculate $F$ statistics. J. Hered. 86, 385-386.

Gutiérrez, J.P., Goyache, F., 2005. A note on ENDOG: a computer program for analysing pedigree information. J. Anim. Breed. Genet. 122, 172-176.

Gutiérrez, J.P., Marmi, J., Goyache, F., Jordana, J., 2005a. Pedigree information reveals moderate to high levels of inbreeding and a weak population structure in the endangered Catalonian donkey breed. J. Anim. Breed. Genet. 122, 378-386.

Gutiérrez, J.P., Royo, L.J., Alvarez, I., Goyache, F., 2005b. MolKin (v.2.0) a computer program for genetic analysis of populations using molecular coancestry information. J. Hered. 96, 718-721.

Hurlbert, S.H., 1971. The non concept of species diversity: a critique and alternative parameters. Ecology 52, 577-586.
Jordana, J., Alexandrino, P., Beja-Pereira, A., Bessa, I., Cañón, J., Carretero, Y., Dunner, S., Laloë, D., Moazami-Goudarzi, K., Sánchez, A., Ferrand, N., 2003. Genetic structure of eighteen local south European beef cattle breeds by comparative F-statistics análisis. J. Anim. Breed. Genet. 120, 73-87.

Kalinowski, S.T., Taper, M.L., Marshall, T.C., 2007. Revising how the computer program CERVUS accommodates genotyping error increases success in paternity assignment. Mol. Ecol. 16, 1099-1106.

Kantanen, J., Olsaker, I., Holm, L.E., Lien, S., Vilkki, J., Brusgaard, K., Eythorsdottir, E., Danell, B., Adalsteinsson, S., 2000. Genetic diversity and population structure of 20 North European cattle breeds. J. Hered. 91, 446-457.

Langella, O., 2002. Populations 1.2.28. Logiciel de Génétique des Populations. Laboratoire Populations, Génétique et Évolution, CNRS UPR 9034, Gif-surYvette. (http://www.cnrs-gif.fr/pge/bioinfo/populations/).

Laval, G., San Cristobal, M., Chevalet, C., 2002. Measuring genetic distances between breeds: use of some distances in various short term evolution models. Gen. Sel. Evol. 34, 481-507.

Luikart, G., Cornuet, J.M., 1998. Empirical evaluation of a test for identifying recently bottlenecked populations from allele frequency data. Conserv. Biol. 12, 228-237.

Ohta, T., Kimura, M., 1973. A model of mutation appropriate to estimate the number of electrophoretically detectable alleles in a finite population. Genet. Res. Cambr. 22, 201-204.

Parés, P.M., Francesch, A., Jordana, J., Such, X., 2005. Catalans de Pèl i Ploma. Races domèstiques autòctones de Catalunya-. Lynx Edicions, Bellaterra, Barcelona, Spain.

Petit, R.J., El Mousadik, A., Pons, O., 1998. Identifying populations for conservation on the basis of genetic markers. Conserv. Biol. 12, 844-855.

Piry, S., Luikart, G., Cornuet, J.M., 1999. BOTTLENECK: a computer program for detecting recent reductions in the effective population size using allele frequency data. J. Hered. 90, 502-503.

Pritchard, J.K., Stephens, M., Donnelly, P., 2000. Inference of population structure using multilocus genotype data. Genetics 155, 945-959.

Reynolds, J., Weir, B.S., Cockerham, C.C., 1983. Estimation of the coancestry coefficient: basis for a short-term genetic distance. Genetics 105, 767-769.

Saitou, N., Nei, M., 1987. The neighbor-joining method: a new method for reconstructing phylogenetic trees. Mol. Biol. Evol. 4, 406-425.

SAS, 2004. SAS Institute Inc., SAS ${ }^{\circledR}$ 9.1.2. Qualification Tools User's Guide, Cary, NC, USA.

Servei de Producció Ramadera, 2003. Situació actual i actuacions per a les races autòctones de Catalunya. Catalunya Rural i Agrària 96, 19-22.

Sobral, M.F., Roberto, C., Navas, D., Palmilha, I., Lima, M.B., Cravador, A., 2009. Identification of descendants of an extinct bovine population from the Algarve region of Portugal using numerical taxonomy analysis of morphological traits. J. Anim. Breed. Genet. 126, 319-326.

Van Oosterhout, C., Hutchinson, W.F., Wills, D.P.M., Shipley, P., 2004. MICROCHECKER: software for identifying and correcting genotyping errors in microsatellite data. Mol. Ecol. Notes 4, 535-538.

Wright, S., 1965. The interpretation of population structure by F-statistics with special regard to systems of mating. Evolution 19, 395-420. 